\title{
Serendipitous and Targeted Synthesis of High Nuclearity Clusters-Carbonate and Oxalate Encapsulating Silver Alkynides
}

\author{
Arvind Kumar Gupta and Andreas Orthaber*
}

Cite This: Cryst. Growth Des. 2020, 20, 4232-4237

Read Online

ABSTRACT: Silver coordination compounds of the $\left[\mathrm{Ag}_{3} \mathrm{~L}_{2}\right]$ (where $\mathrm{L}={ }^{t} \mathrm{Bu}-\mathrm{C} \equiv \mathrm{C}$ ) family having perchlorate counterions exhibit template-driven self-assembly of the common square pyramidal building block. This behavior is similar to previously described observations; however, important differences arise from counterion-silver interactions. Penta- and hexameric clusters encapsulating chloride and oxalate, respectively, were crystallographically characterized. A high nuclearity cluster $\left[\left(\mathrm{CO}_{3}\right)_{3}\left(\mathrm{H}_{2} \mathrm{O}\right) \subset \mathrm{Ag}_{38} \mathrm{~L}_{20}\right]^{12+}$ was formed upon extended exposure to an ambient atmosphere by trapping three carbonates and one water molecule.

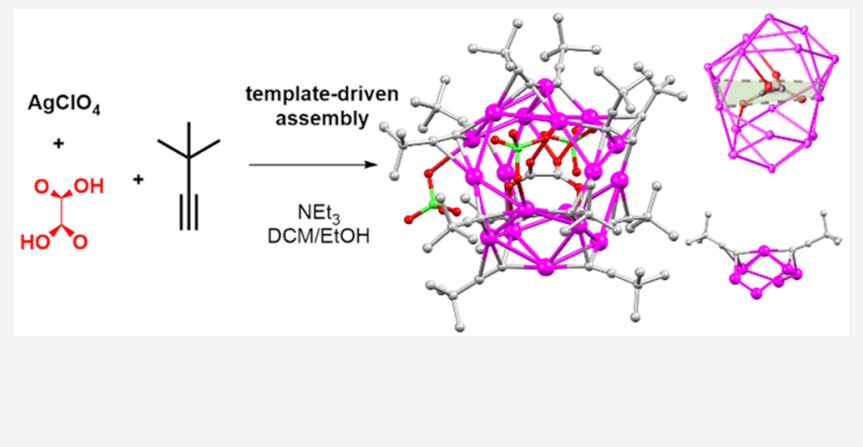

T he silver alkynide clusters with their vast structural diversity have fascinated researchers for many decades. ${ }^{1}$ Structural reports on extraordinarily high nuclearity clusters as well as detailed studies of their optical, electronic, and responsive properties have been reported displaying the broad range of possible applications. ${ }^{2-5}$ Encapsulation of small ions (e.g., halides), ${ }^{6,7}$ oxo-anions (e.g., $\mathrm{NO}_{3}{ }^{-}, \mathrm{ClO}_{4}{ }^{-}$, $\left.\mathrm{CrO}_{4}{ }^{2-}, \mathrm{AsO}_{4}{ }^{3-}, \mathrm{SO}_{4}{ }^{2-}, \mathrm{VO}_{4}{ }^{3-}\right),{ }^{8-11}$ or larger anionic inorganic entities (e.g., polyoxometallates) ${ }^{12,13}$ leads to fascinating structures and high nuclearity silver clusters. In contrast, large clusters exclusively obtained by variation of the steric demand at the alkynide ligands are rare, ${ }^{14}$ but fascinating examples of optically active silver clusters with, e.g., carboranylethynyl ligands have been prepared. ${ }^{15,16}$ Coordinating anions (e.g., triflate, trifluoroacetic acid) or coligands (polyphosphines, pyridine carboxylic acids) afford high nuclearity clusters or extended coordination polymers by binding of the coligand or counterion interactions at the periphery of the metal core. ${ }^{6,17-20}$ Combining alkynyl coordination within mixed multidentate (ethynyl/nitrogen) ligand affords a variety of complex cluster motifs with interesting properties. ${ }^{18,21}$ Alternatively, a large silver cluster was obtained by encapsulation of two squarate dianions-with the flat organic carboxylates stacked above each other-giving rise to a barrel-shaped 24-nuclear silver core. ${ }^{22}$ Another approach to high nuclearity clusters is seen by core expansions from smaller alkynides clusters, e.g., the formation of

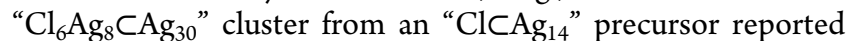
by Mak and co-workers. ${ }^{23}$ The diverse coordination modes and the structural diversity that can be obtained using simple alkynyl ligands and silver salts has fueled research for many decades. $^{24,25}$ In our recent study, we explored the formation of silver clusters and polymers using the sterically demanding ${ }^{t} \mathrm{Bu}$ acetylene (L-H) and a simple silver salt with noncoordinating hexafluorophosphate counterions $\left(\mathrm{AgPF}_{6}\right)$. Therein, we reported the arrangement a square pyramidal building block-innate to the polymer $\left[\mathrm{Ag}_{3} \mathrm{~L}_{2}\right]_{n}\left(\mathrm{PF}_{6}\right)_{n}$-into a series of oligomers (tetra- $\left.\left[\mathrm{Ag}_{3} \mathrm{~L}_{2}\right]_{4}\left(\mathrm{PF}_{6}\right)_{4}\right]$, penta- $\left[\mathrm{XC}\left(\mathrm{Ag}_{3} \mathrm{~L}_{2}\right)_{5}\right]$ $\left(\mathrm{PF}_{6}\right)_{4}$, and hexamer $\left.\left.\left[\left(\mathrm{PF}_{6}\right) \subset\left(\mathrm{Ag}_{3} \mathrm{~L}_{2}\right)_{6}\right]\left(\mathrm{PF}_{6}\right)_{5}\right]\right)$ depending on the provided template and or reaction conditions. ${ }^{26}$ In the current study, we further explored the reactivity of $\left[\mathrm{Ag}_{3} \mathrm{~L}_{2}\right]$ silver alkynides using the coordinating perchlorate $\left(\mathrm{ClO}_{4}^{-}\right)$ counterion. We have found that the square pyramidal motif is also very common to this system; however, interactions of the counterions as well as different encapsulation pathways influence the formation of high nuclearity clusters.

Silver perchlorate cleanly reacts with ${ }^{t} \mathrm{Bu}$ acetylene in dichloromethane (DCM) and ethanol in the presence of base to afford the polymeric compound $\mathbf{1}\left[\mathrm{Ag}_{3} \mathrm{~L}_{2}\right]_{n}\left(\mathrm{ClO}_{4}\right)_{n}$ as a white precipitate. Single crystals of this material can be obtained by slow evaporation of the solvents as colorless plates. Despite heavy twinning along a shear plane, we were able to solve the structure in the triclinic space group $P \overline{1}$ (No. 2). The structure is very similar to the hexafluoro phosphate ${ }^{26}$ and tetrafluoro borate polymer ${ }^{27}$ within the $\mathrm{Ag}_{3} \mathrm{~L}_{2}$ family. The perchlorate counterions are positioned alternatingly above and below the common base of the common square planes along the $1 \mathrm{D}$-polymer chain. The alkynide coordinate in the

Received: April 29, 2020

Revised: May 27, 2020

Published: June 4, 2020 
expected $\mu_{3}-\eta^{1} \eta^{2} \eta^{2}$ modes regularly capping the trigonal faces, with one of the alkynides being disordered, where a $\mu_{3}-\eta^{1} \eta^{1} \eta^{1}$ is realized in one and a $\mu_{3}-\eta^{1} \eta^{1} \eta^{2}$ mode in the other position. The square plane (Ag-Ag 3.055(4), 3.414(5), 3.763(5), and 3.832(5) $\AA$ ) shows short distances between oxygen and silver atoms $\left(\mathrm{Ag} \cdots \mathrm{O}\right.$ from $2.88(2) \AA$ to $3.19(2) \AA, \sum($ vdW radii $)=$ $3.24 \AA$ ) resulting in a distortion of the square pyramidal silver repeating units. One significantly shortened $\mathrm{Ag}-\mathrm{Ag}$ distance of $3.055(4) \AA$ is seen proximal to the perchlorate indicating that the $\mathrm{O} \cdots \mathrm{Ag}$ interactions enforces the argentophilic interactions. This is in contrast to the previously reported hexafluorophosphate structure $\left[\mathrm{Ag}_{3} \mathrm{~L}_{2}\right]_{n}\left(\mathrm{PF}_{6}\right)_{n}$ where the short $\mathrm{Ag}-\mathrm{Ag}$ distance are beyond $3.4 \AA$ and the two longer silver distances are close to $4 \AA^{26}$ For comparison, we have also synthesized the corresponding hexafluoro antimonate polymer $\left[\mathrm{Ag}_{3} \mathrm{~L}_{2}\right]_{n}\left(\mathrm{SbF}_{6}\right)_{n}(\mathbf{1 b})$ to illustrate the impact of coordinating anions. Again, two short and two long distances of 3.5 and 4.0 $\AA$ are realized in the square plane, and no significant $\mathrm{Ag} \cdots \mathrm{F}$ interactions are observed (Figure $1 \mathrm{~b}$ ) illustrating its structural similarity to the hexafluorophosphate structure.
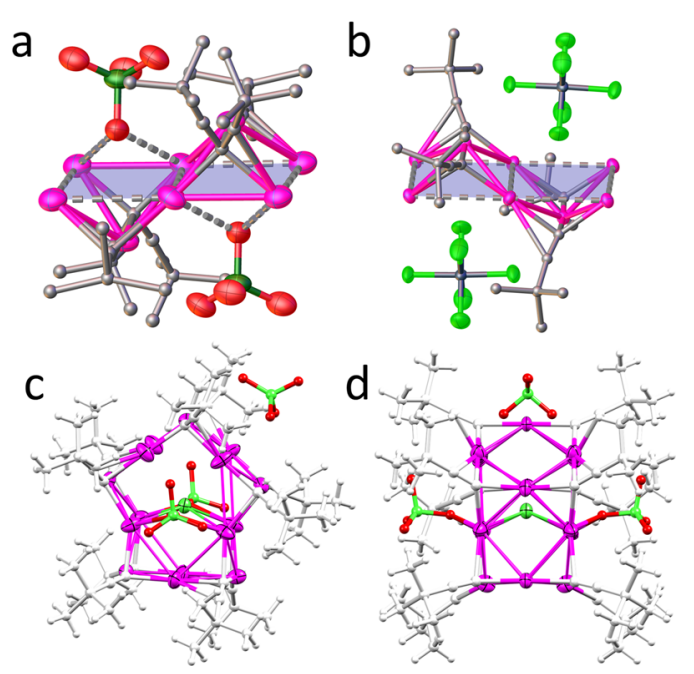

Figure 1. ORTEP representation of the polymeric starting material 1 (a) and the corresponding hexafluoroantimonate polymer $\left[\mathrm{Ag}_{3} \mathrm{~L}_{2}\right]_{n}\left(\mathrm{SbF}_{6}\right)_{n} \mathbf{1 b}$ (b). Solid-state structure of the chloride encapsulating cluster 2 (c: front view; d: side view). Ellipsoids are drawn at a $50 \%$ probability level. Colors: $\mathrm{Ag}$ pink, $\mathrm{Cl}$ green, $\mathrm{O}$ red, $\mathrm{F}$ light green, $\mathrm{Sb}$ dark green, $\mathrm{C}, \mathrm{H}$ gray.
Similar to our previous observation, addition of tetrabutyl ammonium chloride (TBA-Cl) during the reaction affords a pentamer $\left[\mathrm{ClC}\left(\mathrm{Ag}_{3} \mathrm{~L}_{2}\right)_{5}\right]\left(\mathrm{ClO}_{4}\right)_{4}$ of the $\mathrm{Ag}_{3} \mathrm{~L}_{2}$ repeating unit (2). The structure solves in the orthorhombic space group Pnma (No. 62) and contains four molecules in the unit cell. The structure displays a distorted pentagonal prismatic arrangement asymmetrically encapsulating the chloride. In contrast to the alternating apical positions above and below the pyramid's base in the polymer, all apexes are directed outward within the pentameric motif. This necessitates an uncoiling of the polymer during encapsulation. We assume that in solution small fragments of the polymer assemble with a reorientation aided by the template.

Perchlorates are capping the pentagonal faces (Figure 1c) with short $\mathrm{Ag}-\mathrm{O}$ distances, the shortest being just 2.52(1) $\AA$, and one perchlorate at the side of the prismatic core

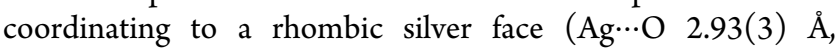
Figure 1c). Similar to polymer 1, the alkynide ligands exhibit the two $\mu_{3}-\eta^{1} \eta^{1} \eta^{1}$ and $\mu_{3}-\eta^{1} \eta^{1} \eta^{2}$ coordination modes. The encapsulated chloride is in close contact with four silver atoms (Ag4-Cl1G 2.906(4), Ag8-Cl1G 2.995(4) A) leading to the distortion of the pentagonal faces. Powder XRD studies of these materials, however, suggest that the cluster $\mathbf{2}$ is not the sole product of this reaction, which is in stark contrast to the clean formation of the corresponding hexafluorophosphate pentamer. We speculate that the chloride encapsulation is competing with the perchlorate interactions and thus diversifies the reactivity.

The chloride encapsulating cluster 2 can be obtained directly from the alkyne and silver salt, and TBA-Cl in the presence of base, but can also form upon addition of TBA-Cl to a solution/ suspension of preformed polymer 1. Notably, prolonged exposure of a solution of polymer 1 to ambient atmosphere resulted upon solvent evaporation in new crystals of a different shape. These were identified by single crystal X-ray diffraction as a large silver cluster ( 3 , Scheme 1$)$ containing 38 silver atoms arranged around three encapsulated carbonates and a water molecule $\left[\left(\mathrm{CO}_{3}\right)_{3}\left(\mathrm{H}_{2} \mathrm{O}\right) \subset \mathrm{Ag}_{38} \mathrm{~L}_{20}\right]\left(\mathrm{ClO}_{4}\right)_{12}$. The serendipitous carbonate encapsulation is not unprecedented. Q.-M. Wang and co-workers also observed carbonate encapsulation forming heptadeca- and nonadecanuclear silver clusters, depending on the employed counterion. ${ }^{28}$ Similarly, atmospheric $\mathrm{CO}_{2}$ trapping into silver alkynide clusters was observed by $\mathrm{Lu}$ and co-workers. ${ }^{29}$ The structure is highly irregular and has very little resemblance to the polymeric material, but is

Scheme 1. Synthesis of the Coordination Polymer $\left[\mathrm{Ag}_{3} \mathrm{~L}_{2}\right]_{n}\left(\mathrm{ClO}_{4}\right)_{n}$ and the Carbonate Encapsulating 38-Nuclear Cluster (3) ${ }^{a}$

(3)

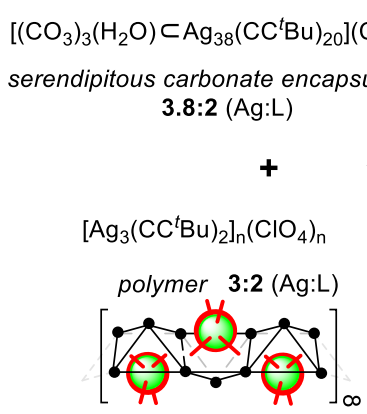

$Y=\mathrm{ClO}_{4}$

$\bullet=\mathrm{Ag}$

${ }^{a}$ Chloride encapsulation leading to the pentadecanuclear pentameric motif (2). (i) DCM/EtOH, NEt 3 ; (ii) $\mathrm{DCM} / \mathrm{EtOH} \mathrm{NEt}{ }_{3}$; $\mathrm{TBA}^{-\mathrm{Cl}}$; (iii) $\mathrm{DCM} / \mathrm{EtOH}, \mathrm{TBA}-\mathrm{Cl}$. The ratios in bold face indicate the silver:ligand ratio of the different coordination compounds. 

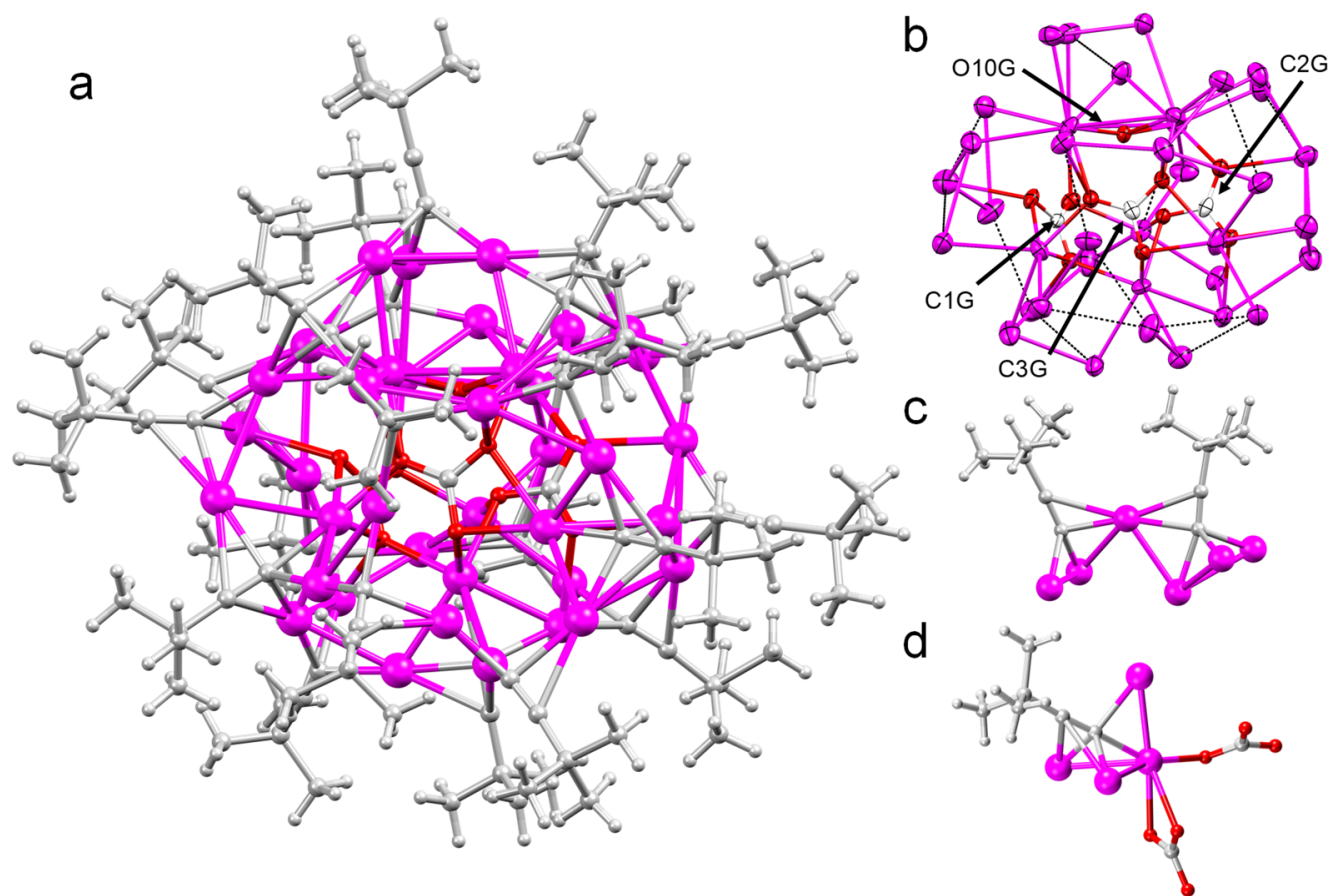

Figure 2. (a) Ball and stick model of the 38-nuclear silver cluster 3 (perchlorate counterions are omitted for clarity). (b) ORTEP plot of the cluster core including the three carbonates (C1G, C2G, C3G) and the water molecule (O10G). Ellipsoids are drawn at a 50\% probability level. (c) Silver atom (Ag1) sandwiched between two $\eta^{2}$ coordinating alkynides (the motif is truncated at the first coordination sphere of the two alkynides). (d) Typical silver environment (Ag7) with bridging $\left(\mu_{4}-\eta^{1} \eta^{1} \eta^{2} \eta^{2}\right)$ of alkynide, three Ag atoms, and two carbonates completing the coordination sphere around $\mathrm{Ag} 7$ with a formal coordination number of seven. Colors: Ag pink, O red, C,H gray.

Scheme 2. Synthesis of Oxalate Encapsulating Cluster 4 (Top) and Attempted L-(+)-Tartrate Encapsulation (Bottom) ${ }^{a}$

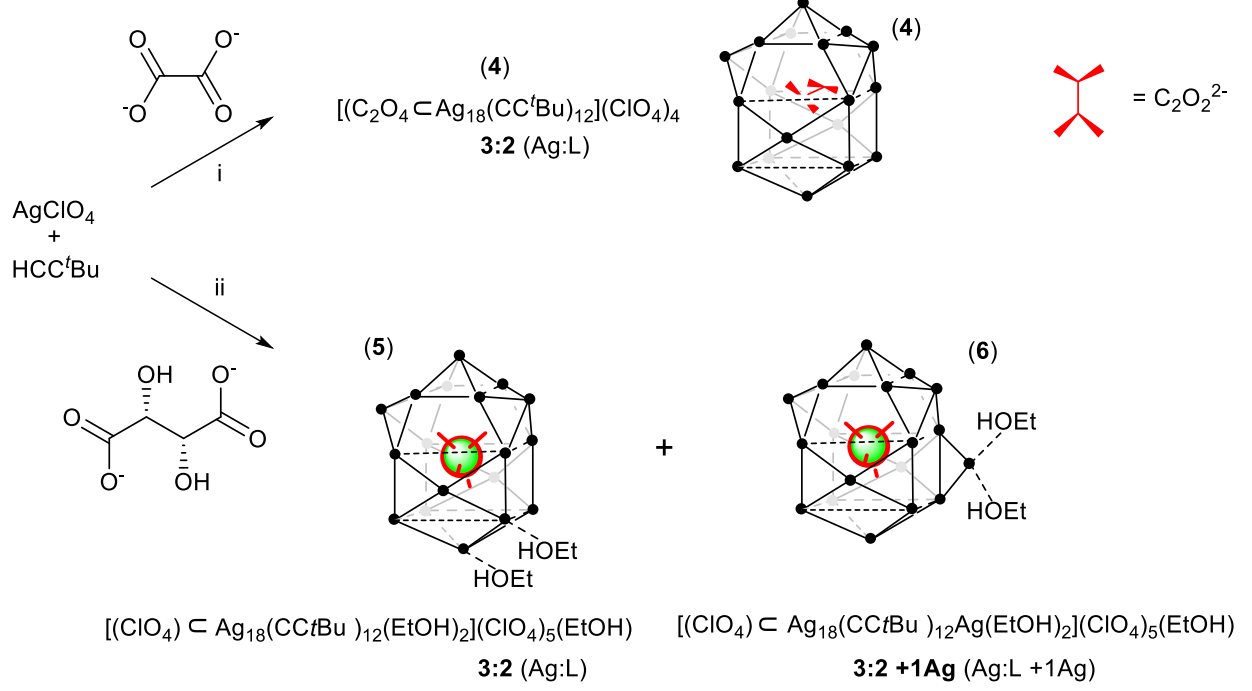

${ }^{a_{T}}$ The latter forming the perchlorate encapsulating clusters (5) and (6). Conditions: (i) DCM/EtOH NEt ${ }_{3}\left(\mathrm{NH}_{4}\right)_{2}\left(\mathrm{C}_{2} \mathrm{O}_{4}\right),(\mathrm{ii}) \mathrm{DCM} / \mathrm{EtOH} \mathrm{NEt}_{3}$ $\mathrm{L}-(+)-\left(\mathrm{NH}_{4}\right)_{2}\left(\mathrm{C}_{4} \mathrm{H}_{2} \mathrm{O}_{6}\right)$. Bold numbers and ratios indicate the silver:ligand ratio of the clusters.

dominated by various short carbonate- $\mathrm{O}-\mathrm{Ag}(2.260(5)$ to $2.578(5) \AA$ and water-O-Ag interactions $(2.169(5)$ to $2.387(5)$ $\AA)$ at the center of the cluster. Formation of such irregular shapes is very typical for high nuclearity silver clusters and reflects the adaptability of the alkynide coordination as well as the omnidirectionality of argentophilic interactions. Besides the common $\mu_{3}$ coordination mode of alkynides capping triangular silver faces $\left(\mu_{3}-\eta^{1} \eta^{1} \eta^{1}, \mu_{3}-\eta^{1} \eta^{1} \eta^{2}, \mu_{3}-\eta^{1} \eta^{2} \eta^{2}\right)$, higher bridging modes $\left(\mu_{4}-\eta^{1} \eta^{1} \eta^{2} \eta^{2}\right.$ and $\left.\mu_{4}-\eta^{1} \eta^{2} \eta^{2} \eta^{2}\right)$ have been realized. An example of a sandwiched silver atom, depicted in
Figure 2c, was realized three times in this structure. Another aspect of this high nuclearity cluster are the high coordination numbers $(\geq 6)$ around certain silver centers. An example of a $\mathrm{CN}=7$ is depicted for the environment around Ag7 (Figure 2d) illustrating the effects of multiple argentophilic interactions. The outer ligand sphere is dominated by the ${ }^{t} \mathrm{Bu}$ groups, but also tightly packed with the perchlorate counterions (Figure 2a and Supporting Information). Notably, 10 out of the 12 perchlorates are in direct contact with the silver core showing the importance of counterion interactions. 
Intrigued by the carbonate encapsulation, we investigated how this silver system responds to organic carboxylates, i.e., performing reactions in the presence of ammonium oxalate and ammonium L-(+)-tartrate. In contrast to our previous findings in which the oxalate could not be incorporated as a guest into a silver cluster, we confirmed the formation of a twistedhexameric silver cluster motif encapsulating the oxalate dianion (4, Scheme 2) using single crystal X-ray analysis (Figure 3).

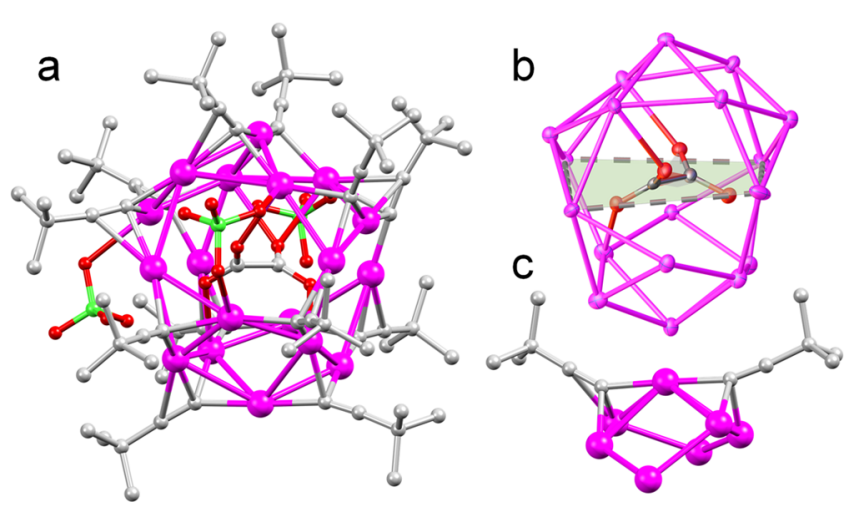

Figure 3. Oxalate encapsulating cluster 4 (a). ORTEP plot of the cluster core (thermal ellipsoids 50\%) with a mean squares plane (m.s.pl.) through the silver atoms Ag20, Ag24, Ag30, and Ag36 dissecting the encapsulated oxalate (b). Pyramidal building block illustrating the $\mu_{3}-\eta^{1} \eta^{1} \eta^{1}$ and $\mu_{3}-\eta^{1} \eta^{1} \eta^{2}$ coordination modes (c). Colors: $\mathrm{Ag}$ pink, $\mathrm{O}$ red, $\mathrm{Cl}$ green, $\mathrm{C}$ gray.

This structure can be described by three pyramids forming a widened square base joint by three further pyramids that are rotated by $90^{\circ}$ (Figure $3 \mathrm{~b}$ ). This contrasts the previously formed hexamer having a hexagonal prismatic silver core, which was formed upon $\mathrm{PF}_{6}{ }^{-}$encapsulation. ${ }^{26}$ The twisted hexamer silver core leads to a number of direct $\mathrm{Ag}-\mathrm{O}$ contacts in the range of 2.445(8) to 2.585(8) $\AA$, and several short Ag... O interactions $(<3.2 \AA)$. The oxalate carbon atoms lie on the plane spanned by the four silver atoms at which the two halves of the twisted hexamer are joint. This causes significant elongation at these sides of the pyramidal building block much beyond argentophilic interactions ( 5.4 to $5.8 \AA$ ). The carboxylates are slightly twisted out of this plane by around $30^{\circ}$. Only the $\mu_{3}-\eta^{1} \eta^{1} \eta^{1}$ and $\mu_{3}-\eta^{1} \eta^{1} \eta^{2}$ coordination modes, which have also been found in our previous work on the $\left[\mathrm{Ag}_{3} \mathrm{~L}_{2}\right]$-family, are realized in this twisted hexameric structure. An example of that is depicted in Figure $3 \mathrm{c}$ where both modes are combined forming the apex of a pyramidal building block.

Increasing the size of the organic carboxylate to tartrate anions renders them unsuitable templates; thus, clean formation of a single product is prohibited. Quite interestingly, we were able to identify two products in which the perchlorate counterions acts as the template. These are octadeca- and nonadecanuclear clusters 5 and 6, respectively (Figure 4). Similar perchlorate encapsulation has previously been observed by Mak et al. in which two perchlorate encapsulating octadecanuclear clusters are linked by short argentophilic interactions. ${ }^{8}$ Cluster 5 can be described in analogy to $\mathbf{4}$ as a twisted hexamer with some moderate $\mathrm{Cl}-\mathrm{O} \cdots \mathrm{Ag}$ distances of the encapsulated perchlorate and several outer-sphere counterions. Notably, two EtOH solvent molecules are directly coordinating to neighboring silver atoms at the apex and base of a pyramid, respectively. This additional coordination by two ethanol molecules presumably blocked the formation of
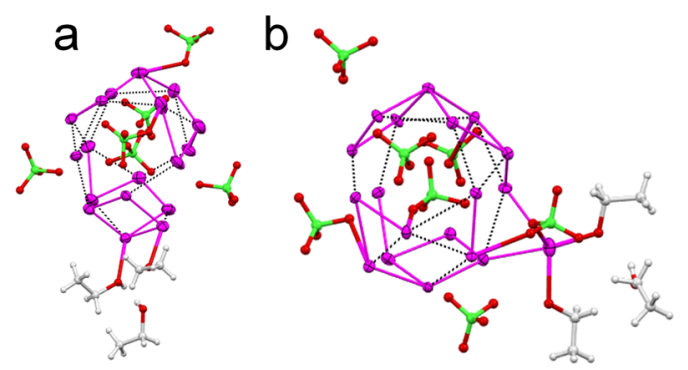

Figure 4. Core of the perchlorate encapsulating clusters 5 and 6 having an octadecanuclear (a) and nonadecanuclear (b) silver cores, respectively. Silver atoms are depicted with thermal ellipsoids (50\%). Acetylide ligands are omitted for clarity. Colors: Ag pink, O red, 1 green, C gray.

intercluster argentophilic interactions as observed by Mak and co-workers. ${ }^{8}$ The nonadecanuclear cluster 6 has great resemblance to 4 and 5 . Close inspection of the metallic core reveals that a single silver atom is added over the basal side of a pyramid. This additional silver center is directly coordinated by two EtOH molecules, and holds a third EtOH molecule hydrogen-bonded in the outer coordination sphere. The behavior in the formation of 6 , i.e., abandoning the original 3:2 silver to ligand ratio, is very indicative of an uncontrolled reactivity during the preparations in the absence of suitable templates.

\section{CONCLUSIONS}

In summary, we have shown that template-driven assembly of pyramidal silver alkynide building blocks can be extended to coordinating counterions, as well as organic carboxylates forming interesting penta- $\left(\mathrm{Ag}_{15}\right)$ and hexameric $\left(\mathrm{Ag}_{18}\right)$ clusters by chloride and oxalate encapsulation, respectively. Long-term exposure to ambient atmosphere leads to $\mathrm{CO}_{2}$ capture which incorporates as three carbonates in a high nuclearity $\mathrm{Ag}_{38}$ cluster. Perchlorate encapsulation was also seen in the hexamer as well as a closely related nonadecanuclear cluster.

\section{EXPERIMENTAL NOTES}

All manipulations were carried out under normal atmosphere with chemicals as received (Sigma-Aldrich, Fluorochem). DCM was distilled over $\mathrm{CaH}_{2}$ prior to use. Single crystal Xray diffraction was performed on a Bruker D8/APEX-II with a Mo $\mathrm{K}_{\alpha} \mu$-source. Structures were solved and refined using the SHELX-suit of programs ${ }^{30,31}$ and the OLEX2. ${ }^{32}$ Further details can be found in the Supporting Information. Further crystallographic details can be obtained free of charge from the CSD quoting the entries 1999484-1999491.

Synthesis and crystallographic details of $\mathbf{1}:\left[\mathrm{Ag}_{3}(\mathrm{C} \equiv\right.$ $\left.\left.\mathrm{C}^{t} \mathrm{Bu}\right)_{2}\right]_{n}\left(\mathrm{ClO}_{4}\right)_{n}$ : A solution of ${ }^{t} \mathrm{BuC} \equiv \mathrm{CH}$ (50 mg, 0.61 $\mathrm{mmol})$ in $\mathrm{CH}_{2} \mathrm{Cl}_{2} / \mathrm{EtOH}$ was treated with $\mathrm{AgClO}_{4}(190 \mathrm{mg}$, $0.91 \mathrm{mmol}$ ) and a few drops of $\mathrm{NEt}_{3}$. The clear solution was stirred for $1 \mathrm{~h}$ after which the reaction mixture was filtered through a Celite pad and kept for crystallization. Colorless needle-shaped crystals were obtained after 1 week upon slow evaporation. Yield $75 \%$ (133 mg).

Synthesis and crystallographic details of 4: $\left[\left(\mathrm{C}_{2} \mathrm{O}_{4}\right) \subset \mathrm{Ag}_{18}\left(\mathrm{C} \equiv \mathrm{C}^{t} \mathrm{Bu}\right)_{12}\right]\left(\mathrm{ClO}_{4}\right)_{4}$ : A solution of ${ }^{t} \mathrm{BuC} \equiv$ $\mathrm{CH}(50 \mathrm{mg}, 0.61 \mathrm{mmol})$ in $\mathrm{CH}_{2} \mathrm{Cl}_{2} / \mathrm{EtOH}$ was treated with $\mathrm{AgClO}_{4}(190 \mathrm{mg}, 0.91 \mathrm{mmol})$ and a few drops of $\mathrm{NEt}_{3}$. After 1-2 min, a slight excess of ammonium oxalate $\left(\mathrm{NH}_{4}\right)_{2} \mathrm{C}_{2} \mathrm{O}_{4}(9$ 
$\mathrm{mg}, 0.06 \mathrm{mmol}$ ) was added. The reaction mixture was stirred for $20 \mathrm{~h}$ and resulted in an opaque solution. The reaction mixture was filtered through a Celite pad and kept for crystallization. Colorless rock-shaped crystals were obtained after 1 week upon slow evaporation. Yield 60\% (104 mg).

The solid state structure of an analogous compound $\mathbf{2 b}$ was obtained in the reaction of the corresponding $\mathrm{AgSbF}_{6}$ salt in the presence of TBA-Cl. Further details and depictions can be found in the Supporting Information.

\section{ASSOCIATED CONTENT}

\section{(s) Supporting Information}

The Supporting Information is available free of charge at https://pubs.acs.org/doi/10.1021/acs.cgd.0c00585.

Additional experimental details and crystallographic information (PDF)

\section{Accession Codes}

CCDC 1999484-1999491 contain the supplementary crystallographic data for this paper. These data can be obtained free of charge via www.ccdc.cam.ac.uk/data_request/cif, or by emailingdata_request@ccdc.cam.ac.uk, or by contacting The Cambridge Crystallographic Data Centre, 12 Union Road, Cambridge CB2 1EZ, UK; fax: +44 1223336033.

\section{AUTHOR INFORMATION}

\section{Corresponding Author}

Andreas Orthaber - Department of Chemistry - Synthetic Molecular Chemistry. Angström laboratories, Uppsala Universitet, 75120 Uppsala, Sweden; @ orcid.org/0000-00015403-9902; Email: andreas.orthaber@kemi.uu.se

\section{Author}

Arvind Kumar Gupta - Department of Chemistry - Synthetic Molecular Chemistry. Ångström laboratories, Uppsala Universitet, 75120 Uppsala, Sweden

Complete contact information is available at: https://pubs.acs.org/10.1021/acs.cgd.0c00585

\section{Author Contributions}

A.K.G. has performed all experiments. The manuscript was written through contributions of all authors. All authors have given approval to the final version of the manuscript.

\section{Funding}

Swedish Research Council (Vetenskapsrådet), Carl-Trygger Foundation, Stiftelsen Olle-Engkvist-Byggmästare

\section{Notes}

The authors declare no competing financial interest.

\section{ACKNOWLEDGMENTS}

The authors would like to thank the Swedish research council (Vetenskapsrådet), Carl-Trygger foundation, Stiftelsen OlleEngkvist-Byggmästare, Lars-Hiertas Minne and COST action CM1302 Smart Inorganic Polymers (SIPs).

\section{ABBREVIATIONS}

DCM, dichloromethane; TBA-Cl, tetrabutyl ammonium chloride; XRD, X-ray diffraction

\section{REFERENCES}

(1) Wang, Q.-M.; Lin, Y.-M.; Liu, K.-G. Role of Anions Associated with the Formation and Properties of Silver Clusters. Acc. Chem. Res. 2015, 48, 1570-1579.

(2) Yam, V. W.-W.; Au, V. K.-M.; Leung, S. Y.-L. Light-Emitting Self-Assembled Materials Based on $\mathrm{d} 8$ and $\mathrm{d} 10$ Transition Metal Complexes. Chem. Rev. 2015, 115, 7589-7728.

(3) Yam, V. W.-W. Molecular Design of Transition Metal Alkynyl Complexes as Building Blocks for Luminescent Metal-Based Materials: Structural and Photophysical Aspects. Acc. Chem. Res. 2002, 35, 555-563.

(4) Mak, T. C. W.; Zhao, L. Multinuclear Silver Ethynide Supramolecular Synthons for the Construction of Coordination Networks. Chem. - Asian J. 2007, 2, 456-467.

(5) Zhang, S.-S.; Wang, X.; Su, H.-F.; Feng, L.; Wang, Z.; Ding, W.Q.; Blatov, V. A.; Kurmoo, M.; Tung, C.-H.; Sun, D.; Zheng, L.-S. A Water-Stable Cl@Ag14 Cluster Based Metal-Organic Open Framework for Dichromate Trapping and Bacterial Inhibition. Inorg. Chem. 2017, 56, 11891-11899.

(6) Wei, Q.-H.; Zhang, L.-Y.; Shi, L.-X.; Chen, Z.-N. Octahedral hexanuclear silver(I) and copper(I) ferrocenylacetylide complexes. Inorg. Chem. Commun. 2004, 7, 286-288.

(7) Shen, H.; Kubo, K.; Kume, S.; Zhang, L.; Mizuta, T. Novel chloride-centered Ag18 clusters featuring a cuboctahedral Ag12 skeleton. Dalton Trans. 2017, 46, 16199-16204.

(8) Hau, S. C. K.; Cheng, P.-S.; Mak, T. C. W. Ligand-Induced Assembly of Coordination Chains and Columns Containing HighNuclearity Silver(I) Ethynide Cluster Units. Organometallics 2014, 33, 3231-3234.

(9) Bian, S.-D.; Wu, H.-B.; Wang, Q.-M. A Facile Template Approach to High-Nuclearity Silver(I) Alkynyl Clusters. Angew. Chem., Int. Ed. 2009, 48, 5363-5365.

(10) Li, J.-Z.; Bigdeli, F.; Gao, X.-M.; Wang, R.; Wei, X.-W.; Yan, X.W.; Hu, M.-L.; Liu, K.-G.; Morsali, A. Trivalent Tetrahedral Anion Template: A 26-Nucleus Silver Alkynyl Cluster Encapsulating Vanadate. Inorg. Chem. 2019, 58, 5397-5400.

(11) Liu, K.-G.; Wei, X.-W.; Bigdeli, F.; Gao, X.-M.; Li, J.-Z.; Yan, X.-W.; Hu, M.-L.; Morsali, A. Investigation of the Effect of a MixedLigand on the Accommodation of a Templating Molecule into the Structure of High-Nucleus Silver Clusters. Inorg. Chem. 2020, 59, $2248-2254$.

(12) Gao, G.-G.; Cheng, P.-S.; Mak, T. C. W. Acid-Induced Surface Functionalization of Polyoxometalate by Enclosure in a Polyhedral Silver-Alkynyl Cage. J. Am. Chem. Soc. 2009, 131, 18257-18259.

(13) Qiao, J.; Shi, K.; Wang, Q.-M. A Giant Silver Alkynyl Cage with Sixty Silver(I) Ions Clustered around Polyoxometalate Templates. Angew. Chem., Int. Ed. 2010, 49, 1765-1767.

(14) Zhang, R.; Hao, X.; Li, X.; Zhou, Z.; Sun, J.; Cao, R. Soluble Silver Acetylide for the Construction and Structural Conversion of All-Alkynyl-Stabilized High-Nuclearity Homoleptic Silver Clusters. Cryst. Growth Des. 2015, 15, 2505-2513.

(15) Hailmann, M.; Wolf, N.; Renner, R.; Schäfer, T. C.; Hupp, B.; Steffen, A.; Finze, M. Unprecedented Efficient Structure Controlled Phosphorescence of Silver(I) Clusters Stabilized by Carba-closododecaboranylethynyl Ligands. Angew. Chem., Int. Ed. 2016, 55, 10507-10511.

(16) Hailmann, M.; Wolf, N.; Renner, R.; Hupp, B.; Steffen, A.; Finze, M. Silver(I) Clusters with Carba-closo-dodecaboranylethynyl Ligands: Synthesis, Structure, and Phosphorescence. Chem. - Eur. J. 2017, 23, 11684-11693.

(17) Belyaev, A.; Dau, T. M.; Jänis, J.; Grachova, E. V.; Tunik, S. P.; Koshevoy, I. O. Low-Nuclearity Alkynyl d10 Clusters Supported by Chelating Multidentate Phosphines. Organometallics 2016, 35, 37633774.

(18) Zhang, Z.; Li, B.; Meng, X.; Yin, X.; Zhang, T. Assembly of three-dimensional networks based upon silver-ethynide complexes bearing pyridyl and carboxylate groups. Dalton Trans. 2013, 42, $4306-4312$. 
(19) Gupta, A. K.; Orthaber, A. Facile synthesis of silver alkynide cluster and coordination polymers using picolinic acid as a co-ligand. Dalton Trans. 2019, 48, 16518-16524.

(20) Chen, Y.-T.; Krytchankou, I. S.; Karttunen, A. J.; Grachova, E. V.; Tunik, S. P.; Chou, P.-T.; Koshevoy, I. O. Silver AlkynylPhosphine Clusters: An Electronic Effect of the Alkynes Defines Structural Diversity. Organometallics 2017, 36, 480-489.

(21) Zhang, X.; Wang, J.-Y.; Huang, Y.-Z.; Yang, M.; Chen, Z.-N. Silver(i) nanoclusters of carbazole-1,8-bis(acetylide): from visible to near-infrared emission. Chem. Commun. 2019, 55, 6281-6284.

(22) Liu, K.-G.; Chen, S.-K.; Lin, Y.-M.; Wang, Q.-M. An organic anion template: a 24-nucleus silver cluster encapsulating a squarate dimer. Chem. Commun. 2015, 51, 9896-9898.

(23) Hau, S. C. K.; Cheng, P.-S.; Mak, T. C. W. Enlargement of Globular Silver Alkynide Cluster via Core Transformation. J. Am. Chem. Soc. 2012, 134, 2922-2925.

(24) Gupta, A. K.; Orthaber, A. Alkynyl coinage metal clusters and complexes - Syntheses, structures, and strategies. Chem. - Eur. J. 2018, 24, 7536-7559.

(25) Nast, R. Coordination chemistry of metal alkynyl compounds. Coord. Chem. Rev. 1982, 47, 89-124.

(26) Gupta, A. K.; Orthaber, A. The self-assembly of $\left[\left\{\mathrm{Ag}_{3}\left(\mathrm{C} \equiv \mathrm{C}^{t} \mathrm{Bu}\right)_{2}\right\}_{\mathrm{n}}\right]^{\mathrm{n}+}$ building units into a template-free cuboctahedron and anion encapsulating silver cages. Inorg. Chem. 2019, 58, $16236-16240$.

(27) Al-Farhan, K. A.; Abu-Salah, O. M.; Mukhalalati, M.; Jaafar, M. Copper Disordered Hexakis(phenylethynyl)pentaargentate(I) Cluster. Acta Crystallogr., Sect. C: Cryst. Struct. Commun. 1995, 51, 10891092.

(28) Bian, S.-D.; Jia, J.-H.; Wang, Q.-M. High-Nuclearity Silver Clusters Templated by Carbonates Generated from Atmospheric Carbon Dioxide Fixation. J. Am. Chem. Soc. 2009, 131, 3422-3423.

(29) Jin, J.-L.; Shen, Y.-L.; Xie, Y.-P.; Lu, X. Anion Templated Synthesis of Silver(I)-Ethynide Dithiophosphate Clusters. Cryst. Growth Des. 2018, 18, 4372-4377.

(30) Sheldrick, G. Crystal structure refinement with SHELXL. Acta Crystallogr., Sect. C: Struct. Chem. 2015, 71, 3-8.

(31) Sheldrick, G. A short history of SHELX. Acta Crystallogr., Sect. A: Found. Crystallogr. 2008, A64, 112-122.

(32) Dolomanov, O. V.; Bourhis, L. J.; Gildea, R. J.; Howard, J. A. K.; Puschmann, H. OLEX2: a complete structure solution, refinement and analysis program. J. Appl. Crystallogr. 2009, 42, 339-341. 